\title{
Biases in the evaluation of self-harm in patients with disability due to spinal cord injury
}

\author{
Maggi A. Budd ${ }^{1,2} \cdot$ Omar Sultan Haque ${ }^{2} \cdot$ Michael Ashley Stein ${ }^{3}$
}

Received: 10 January 2020 / Revised: 8 May 2020 / Accepted: 11 May 2020

(c) International Spinal Cord Society 2020

\begin{abstract}
Introduction Suicide is a global problem and accurate assessment of risk for self-harm is critical. Even morally principled clinicians can manifest bias when assessing self-harm in patients with physical disabilities such as spinal cord injury (SCI). Assessment of self-harm is an obligation for health care clinicians and overestimating or underestimating risk may undermine a patient's trust in their care, possibly leading to less engagement, increased apathy about having an interest in living, and less adherence to healthy treatment options.

Case presentation Introduces readers to three biases that can impact decision-making regarding a patient with a disability when assessing the patient's risk for self-harm: (1) ineffectual bias, (2) fragile friendliness bias, and (3) catastrophe bias. These preconceptions are derived from a mix of paternalism, projection, low expectations, pity, and infantilization. In this paper, we explain how each bias can affect clinical decision-making regarding diagnosis, treatment, prognosis, and prevention for patients with SCI within a common case scenario. Readers can employ personal reflection and potential selfapplication when they encounter individuals with SCI in and outside clinical settings.

Discussion Unchecked biases toward the disabled and patients with SCI can undermine ethical caregiving. Biases are habits of mind and thoughtful clinical and education interventions can improve clinical practice. The literature on health care bias with other minority groups is instructive for investigating biases related to patients with disabilities, and especially for clinicians outside of rehabilitation medicine.
\end{abstract}

\section{Introduction}

Psychological research has long identified explicit and implicit biases that tend to arise when humans make judgments or decisions. For example, the halo effect is when a general impression of a person, such as attractiveness, positively biases judgments on unrelated characteristics such as intellect or moral character [1].

Bias in health care is a systematic pattern of inaccuracy in social perception that can negatively influence medical

These authors contributed equally: Omar Sultan Haque, Michael Ashley Stein

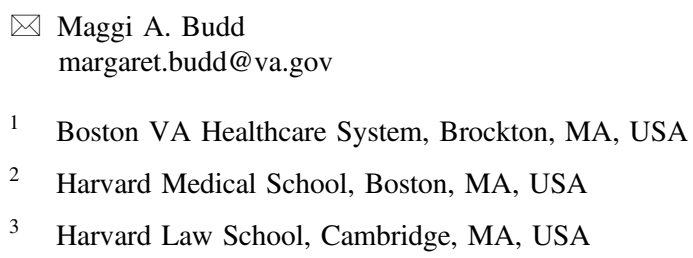

decision-making [2, 3]. In 2003, the Institute of Medicine concluded that unrecognized biases against certain minority groups can affect the care offered and health outcomes for these individuals [4]. These biases are believed to be one cause of health disparities [3-7].

Most research on health disparities has involved racial and ethnic minorities; however, persons with disabilities are also a population with health care disparities [8]. As with racial minorities, persons with disabilities face experiences of prejudice, discrimination, and oppression [9]. The literature on health care bias with other minority groups can be instructive for investigating biases related to patients with disabilities. Unchecked biases in any population can undermine ethical caregiving.

Like other minorities, people with spinal cord injuries (SCI), an identifiable sub-group of patients with physical disabilities, have visible features (e.g., presenting in a wheelchair) that others may use in the formation of bias against them. Bias can be expressed directly (e.g., a clinician noting that "People with severe physical disabilities make me uncomfortable"), or more indirectly (the clinician 
makes eye contact with the caregiver instead of the patient presenting in a wheelchair). Implicit biases are typically not consciously recognized and occur despite best intentions to the contrary $[6,10]$. It is the clinician's role to accurately assess the health status of a patient and treat them effectively and with dignity.

The therapeutic relationship greatly influences clinical outcomes [11]. This relationship is undermined when bias is present, and especially if the clinician denies the possibility of bias being present. Nonetheless, the patient-clinician relationship can be restored if the clinician acknowledges the bias and attempts to correct it [7].

A core part of the patient-clinician relationship is an accurate assessment of a person's risk of self-harm (i.e., self-injury, self-neglect) or suicide. Biases that impair the therapeutic relationship or the decision-making process would result in inaccurate perceptions by the clinician [6] that either overestimate or underestimate risk for self-harm or suicide, which likely alienates patients and harms the therapeutic alliance. Discussing uncomfortable topics can increase the chance for bias [2], therefore, it is important to look at how clinicians and patients interact in these circumstances and then determine what contributes to negative outcomes. The existential discomfort of discussing a patient's interest in living and dying provides a rich opportunity to study occurrences of unconscious bias [2] and the potential reactions from clinicians assessing them.

Another bias found in the perception of people with SCI is that clinicians attribute lower quality of life to their paralyzed patients than the patients report for themselves [12]. Reasons for these biases are complex-and importantly, not deliberate $[3,13]$. Bias can manifest during uncomfortable conversations involving death wishes or explicit suicidal thoughts with patients with SCI. Recognizing bias in the context of assessing risk for self-harm, where accuracy existentially matters, is especially important for people with disabilities, since suicidality is 3.5 times higher among this group as compared with nondisabled adults [14]. Bias can lead to an inaccurate assessment that in turn leads to faulty decision-making, damaging the therapeutic relationship, and causing further harm to people with SCI.

\section{Case presentation}

\section{Three biases and their effects on risk assessment}

There are three biases that likely impact a clinician's decision-making regarding a patient with a disability [15] and these biases also can apply when assessing the patient's risk for self-harm: (1) ineffectual bias, (2) fragile friendliness bias, and (3) catastrophe bias. These preconceptions are derived from a mix of paternalism, projection, low expectations, pity, and infantilization [15]. Each bias impacts clinical decision-making and harms the therapeutic alliance. We explain how each bias can affect clinical decision-making regarding diagnosis, treatment, prognosis, and prevention for patients with SCI within a case scenario: a patient with SCI is hospitalized for poor nutrition and severe pressure wounds. They spend their days sitting in a wheelchair, drinking whiskey, and watching television.

\section{(1) Ineffectual bias}

Persons with disabilities are often perceived as having low agency and diminished competence $[15,16]$. Here the perceiver makes inferences from limited information, such as no longer being capable of ambulating, and applies those inferences to the person's entire mental state. People with disabilities report lived experiences of feeling devalued by others in this specific manner related to the underperception of agency [9]. For instance, one person with quadriplegia noted, "I am either a spectacle or invisible [in public]" (Personal Communication, July 5, 2018). Ineffectual bias in the perception of patients with SCI primarily manifests in clinical paternalism and a diminished therapeutic alliance.

(a) Diagnosis: clinicians are more likely to discount and place less emphasis on the experiences of a patient with SCI in diagnostic formulations, presuming they are not fully competent. Consequently, the quality of the diagnosis is likely reduced. Symptoms of self-destructive intentions may be discounted (e.g., biased perception is "Of course they'd drink and watch TV all day! We cannot expect them to do much of anything else."). Unfortunately, this patient is exercising passive suicidality through self-neglect, which may be overlooked.

(b) Treatment: more conservative treatment options that "they can handle" are more likely to be made. Treatment for patients with SCIs is likely based less on patient preferences and via shared decision-making (e.g., a clinician does not discuss ways for the patient to stop drinking because those strategies are not considered "realistic" suggestions for the patient.).

(c) Prevention: the clinician's efforts are more likely oriented toward external interventions such as the environment, caregivers, and social supports (e.g., fewer efforts to self-motivate the patient for better self-care and healthier life activities. "Maybe we can suggest to the spouse not to buy as much alcohol and perhaps work fewer hours to help them do other things than drink alcohol and watch television?"). Focus is less likely on patients with SCI to improve their own health as partners in intervention planning.

(d) Prognosis: skewed toward the pessimistic. Diminished hope from the clinician adds drain on the therapeutic relationship and the patient's self-efficacy (e.g., "This is the 
Table 1 Ineffectual bias and impact for clinical decision-making of self-harm risk.

\begin{tabular}{|c|c|c|}
\hline Ineffectual bias & Clinical paternalism \& reduced therapeutic alliance & Example biased clinical response \\
\hline Diagnosis & $\begin{array}{l}\text { Symptoms of self-harm may be missed due to an } \\
\text { assumption of less agency. }\end{array}$ & $\begin{array}{l}\text { This lifestyle makes sense and is what they can handle so it is } \\
\text { what we should expect. }\end{array}$ \\
\hline Treatment & More paternalistic/less informed consent. & $\begin{array}{l}\text { Let's primarily focus on wound care and not focus on behaviors } \\
\text { at home. }\end{array}$ \\
\hline Prevention & $\begin{array}{l}\text { Focused externally, rather than on patient's agency for } \\
\text { self-harm. }\end{array}$ & $\begin{array}{l}\text { I will ask the spouse if they have concerns or if the patient needs } \\
\text { anything. }\end{array}$ \\
\hline Prognosis & $\begin{array}{l}\text { More pessimistic due to expected low self-efficacy for } \\
\text { patients to help themselves. }\end{array}$ & This is the best they can do. \\
\hline
\end{tabular}

best we can expect. Maybe drinking is their only source of pleasure?") (Table 1).

\section{(2) Fragile friendliness bias}

There is an increased perception of the person with a disability, such as SCI, to be friendly and fragile [15]. Compared with nondisabled patients, patients with SCI are deemed to be more warm, trustworthy, and prosocial [15]. This fragility bias and saintly bias can result in either overor underestimating risk for self-harm or suicide.

Clinical fragility bias With the over-attribution of fragility, clinicians likely amplify the degree of suffering perceived in patients with SCI, as compared with the same symptoms reported by a person without that disability [15].

(a) Diagnosis: clinicians are likely to overestimate the severity of symptoms; overdiagnose and test (e.g., the patient states that their life is like groundhog's day, with boring redundancy and not much to look forward to, declaring drinking as a rare source of limited pleasure in life. The physician insists that the person speak to the oncall psychiatrist and recommends a full workup on mood disorders and suicidality). This likely results in the patient not wanting to share their experiences with clinicians.

(b) Treatment: the perception of heightened fragility likely leads to more conservative treatment decisions by clinicians, because unpleasant or uncomfortable assessments or interventions will be avoided (e.g., clinicians avoid suggesting interventions with negative side effects; or avoid having direct conversations about the patient's disinterest in living for fear of upsetting the patient further).

(c) Prevention: amidst a perception of high fragility, it is more likely that extreme or unnecessary forms of prevention are enacted (e.g., an order is placed for the patient to have 1:1 supervision throughout this admission even if their suicidality is passive without any intent or plan to harm themselves). The patient likely learns distrust for psychological or psychiatric services and may be less likely to disclose their honest thoughts in the future. (d) Prognosis: clinicians are more likely to underestimate resilience in the patient with SCI, often with suicidal projections of hopelessness onto the patient when none are present (e.g., the clinician may unconsciously think, "This is a permanent condition with no chance of getting better. I would also feel bored and dissatisfied and think about dying too."). With a diminished prognosis for the patient with $\mathrm{SCI}$, the clinician's decision-making is truncated in its hopefulness for possible interventions and biased toward end of life planning.

Clinical saintly bias With the over perception of friendliness and prosociality in patients with SCI, clinicians likely underestimate the darker or dysfunctional sides of patients with SCI, including self-harm, anger problems, sexually transmitted diseases, and marital infidelity. When this quintessentially human side of life minimized, the patient-clinician interaction will be distorted, and the patient will be less likely to feel that they are "allowed to be a regular person," as expressed by Olkin [9].

(a) Diagnosis: not wavering from the saintly script, clinicians are more likely to overlook self-destructive behaviors in their diagnostic formulations (e.g., the rehabilitation team pleasantly provides full treatments without questioning if recent behaviors were an attempt for passive suicidality).

(b)/(c) Treatment/prevention: interventions will be less likely for the same presenting problem if it violates the saintly script (e.g., patient's thoughts regarding deliberate self-harm are more likely to result in clinician thinking, "They are such an inspiration to others and would not hurt themselves. No interventions are needed at this time.").

(d) Prognosis: the saintly view of prognosis more often includes a happy ending, and so is likely biased toward being overly optimistic (e.g., the patient is returned to medical baseline and discharged back home with providers expecting positive health behaviors going forward. How to prevent the patient from becoming medically compromised by sitting in one spot all day drinking whiskey [passive suicide] was not addressed) (Table 2). 
Table 2 Fragile friendliness bias and impact for clinical decision-making of self-harm risk.

\begin{tabular}{|c|c|c|}
\hline \multicolumn{2}{|l|}{$\begin{array}{l}\text { Fragile } \\
\text { friendliness bias }\end{array}$} & \multirow[t]{2}{*}{ Example biased clinical response } \\
\hline $\begin{array}{l}\text { Clinical } \\
\text { fragility bias }\end{array}$ & Overestimates risk \& reduced therapeutic alliance & \\
\hline Diagnosis & Increase likelihood of self-harm related diagnosis. & This patient is clearly suicidal and must be protected. \\
\hline Treatment & $\begin{array}{l}\text { Difficult interventions against self-harm are likely } \\
\text { minimized; when present, interventions are more conservative } \\
\text { due to concern for patient fragility to handle interventions. }\end{array}$ & $\begin{array}{l}\text { They have SCI! Be gentle. Let's not remind them how hard life } \\
\text { is for them. }\end{array}$ \\
\hline Prevention & Excessive self-harm prevention efforts above actual risk. & Order 1:1 supervision for safety even when unnecessary. \\
\hline Prognosis & More pessimistic, resilience is underestimated. & $\begin{array}{l}\text { They cannot help it. If it was me, I would be dissatisfied and } \\
\text { think about dying too. }\end{array}$ \\
\hline $\begin{array}{l}\text { Clinical } \\
\text { saintliness bias }\end{array}$ & Underestimates risk \& reduced therapeutic alliance & \\
\hline Diagnosis & Minimizes likelihood of self-harm related diagnosis. & $\begin{array}{l}\text { They are so inspiring and a good person; they would never } \\
\text { intentionally harm themselves. }\end{array}$ \\
\hline Treatment & $\begin{array}{l}\text { Likelihood of intervention against self-harm minimized; when } \\
\text { present, interventions are more conservative. }\end{array}$ & $\begin{array}{l}\text { Is this treatment really necessary? I may just mention it as a } \\
\text { possibility later on if things get worse. }\end{array}$ \\
\hline Prevention & Self-harm prevention efforts minimized below actual risk. & $\begin{array}{l}\text { Focus on plan for patient discharge home after wounds heal, } \\
\text { without indicated self-harm safety planning for home. }\end{array}$ \\
\hline Prognosis & Overly optimistic prognosis. & $\begin{array}{l}\text { Good nutrition and healed skin will get them back to their } \\
\text { resilient self. }\end{array}$ \\
\hline
\end{tabular}

\section{(3) Catastrophe bias}

Clinicians likely project onto the patient with SCI the clinician's own perceptions of catastrophe for being in the state that the patient is in, and this biases therapeutic interactions toward more perceived suffering and less hope [9]. Quality of life is likely perceived as being much lower than it really is for the patient with SCI. Suffering (hopelessness, wanting to die) is likely overestimated relative to what the person actually experiences. Catastrophe bias likely leads to clinical pessimism, more nocebo (inverse of placebo) effects, and enhanced disconnection between the patient and the clinician.

(a) Diagnosis: more severe diagnoses will likely be given for the same presenting symptoms (e.g., the clinician diagnoses substance use disorder (SUD) without a comprehensive clinical interview when a proper assessment would have ruled out SUD).

(b)/(c) Treatment/prevention: clinicians will more likely assume that the patient with SCI is in mourning or highly distressed over their disablement, and treatment/preventive efforts will be more aggressive than without the catastrophe bias. However, when the catastrophe bias goes beyond a threshold (i.e., the patient is presumed to want to die), treatment will then be less likely since the clinician will embody hopelessness in their treatment planning and "give up" on the patient sooner than they would have otherwise.

(d) Prognosis: diminished expectations for outcomes. Resiliency is underestimated and so is the chance for adaptation or growth (e.g., clinicians expect the same SUD behaviors and an unchanged evaluation on the next visit) (Table 3).

\section{Discussion}

All humans are susceptible to biases, including wellmeaning and morally principled clinicians. Unrecognized biases toward patients with SCI can undermine ethical and effective health care delivery. Explicit and implicit biases can unintentionally affect bidirectional communication between patient and clinician and significantly hinder the therapeutic alliance. Consequences can be detrimental within a medical context when such interactions impact the clinician's ability to accurately assess a patient's risk of selfharm, such as their view on wanting to live or die, to have or to forgo treatments or preventative interventions. For patients with SCI, poor interpersonal experiences with their clinicians can undermine trust in their care, leading to less engagement, perhaps increased apathy about having a disinterest in living, and less adherence to healthy treatment options.

Research on biases in health care toward the physically disabled, such as patients with SCI, is scarce despite the behavioral patterns of avoidance seen in the presence of persons with physical disabilities [17]. We, therefore, call for more research attention on this topic, both for persons with SCI, and patients with disabilities more broadly. 
Table 3 Catastrophe bias and impact for clinical decision-making of self-harm risk.

\begin{tabular}{|c|c|c|}
\hline Catastrophe bias & Clinical pessimism \& reduced therapeutic alliance & Example clinical response \\
\hline Diagnosis & More severe diagnosis for the same presenting symptoms. & $\begin{array}{l}\text { Patient is diagnosed with full SUD even when not } \\
\text { meeting full criteria. }\end{array}$ \\
\hline Treatment & $\begin{array}{l}\text { More aggressive; and then when hopelessness is perceived, more } \\
\text { likely to undertreat/give up, maybe refer to palliative medicine. }\end{array}$ & $\begin{array}{l}\text { We need to do everything to prevent them from dying; vs. } \\
\text { I understand why they want to decline treatment. }\end{array}$ \\
\hline Prevention & Less likely due to increased pessimism. & What is going to happen is going to happen. \\
\hline Prognosis & Less expectation for improvement. & $\begin{array}{l}\text { I expect the same scenario next check-up; what is the } \\
\text { point of asking them to try an intervention? }\end{array}$ \\
\hline
\end{tabular}

Table 4 Current patients with SCI read the paper and shared their thoughts about the described biases.

\begin{tabular}{|c|c|}
\hline \multirow[t]{3}{*}{ Ineffectual bias } & $\begin{array}{l}\text { "Clinical paternalism is very common. A doctor will prescribe medications as if I had no input or that I was } \\
\text { incapable of understanding." }\end{array}$ \\
\hline & "Nurses and even people in stores talk to me like I am a child trapped in an adult body in a big wheelchair." \\
\hline & $\begin{array}{l}\text { "My suggestion is to simply talk to us. Ask questions. Don't just walk into the room and say, 'It's cold in here' and } \\
\text { place five blankets on me." }\end{array}$ \\
\hline \multicolumn{2}{|l|}{ Fragile friendliness bias } \\
\hline Clinical Fragility Bias & $\begin{array}{l}\text { "This is the worst! I think society teaches that people in wheelchairs are inherently weak and 'special,' and that we } \\
\text { may break. They overkill us with apologies and underkill with trying to intervene." }\end{array}$ \\
\hline Clinical Saintly Bias & $\begin{array}{l}\text { "The more compliant and less likely you are to draw attention makes things easier to overlook. Keeps it simpler. } \\
\text { Some newly injured people pull inward and do not want to share honest thoughts for fear that they will be mothered, } \\
\text { or people will not know how to respond, which makes it all worse." }\end{array}$ \\
\hline Catastrophe Bias & $\begin{array}{l}\text { "There is an assumption of anger and resentment. I admit, anger was my first expression following SCI but after } \\
\text { some time, this subsides. People overly assume that we are more annoyed and frustrated than we are. They say, } \\
\text { 'Calm down,' and their misinterpretation that I am upset when I am not makes me feel even worse! A better response } \\
\text { is, 'Are you upset with something?'... Address the issue to that circumstance and not generalize. Don't overblow } \\
\text { things, do not use a cleaver when all you need is a pair of tweezers. We do get frustrated, every human does. } \\
\text { Interacting at that moment is important. Acknowledge that our frustrations are valid is pretty much all that is needed. } \\
\text { Some things will not ever be fixed, and we know this." }\end{array}$ \\
\hline
\end{tabular}

Other interventions should target social psychological biases that impair the care for persons with SCI and the accurate assessment of their risk for self-harm. Implicit biases occur without conscious awareness and are often not in line with one's personal beliefs [13]. Therefore, it may be helpful to conceptualize implicit bias as a "habit of mind" [10] that can be ameliorated through habit-breaking interventions.

Such interventions ought to be both educational and clinical. Education and raising consciousness are paramount [15]. As with all successful changes in behavior, educators, and clinicians must first understand their susceptibility [18]. Faculty who develop and conduct training around bias should prepare for personal and other challenges that may affect implementation in their institutions [7, 19, 20]. For example, intergroup differences such as race and gender, as well as the amount of exposure the clinician has with a certain population, can influence bias [20]. Interventions to raise awareness and improve skills for limiting bias are best when trainees are directly exposed and cooperatively interact with people who have disabilities [18], particularly when patients use wheelchairs [21, 22]. Case studies should be conducted involving actual stakeholders rather than vignettes-for example, patients with SCI like those we treat in our clinics.

All members of the disciplinary team should be involved in efforts to reduce bias because false assumptions about a person's quality of life can change how we present treatment options and negatively influence outcomes [23]. Clinical formulations in rounds should include discussions about biases while at the same time individualizing recommendations for the specific patient [24]. This can be done by a commitment in education and practice to finding out and attending to the patient's actual experience and mental state, rather than deriving perspectives from the heuristic of an identified category or group. Rather than attending to what clinical determinations and interventions do people with SCI require as a generic category, clinicians should ask what factors are this particular person struggling with, and what can be done to increase their health outcomes and resilience? Education efforts should begin at the start of clinical training and include all clinicians who care for individuals with SCI (doctors, physician assistants, physical therapists, occupational therapists, nurses, psychologists, technicians, etc.). It could also be potentially 
helpful to increase the number of clinicians with SCI and other discernable disabilities. In addition to allowing the clinical staff to better reflect the population at large and the patients they care for, such individuals exhibit significantly less bias against people with disabilities, and their presence increases opportunities to see people with SCI or other disabilities in less stereotyped and more empowering roles [25]. Health care professionals, especially those working in areas other than medical rehabilitation, would be more likely to realize that disability is a part of the human condition, and any member of the human family can acquire a disability, sometimes instantly. And undoing disability bias takes much longer than an instant.

Table 4 shows patients from our clinic who read and responded to the biases as described in this.

\section{Compliance with ethical standards}

Conflict of interest The authors declare that they have no conflict of interest.

Publisher's note Springer Nature remains neutral with regard to jurisdictional claims in published maps and institutional affiliations.

\section{References}

1. Thorndike EL. A constant error in psychological ratings. J Appl Psychol. 1920;4:25-9. https://doi.org/10.1037/h0071663

2. Albisser Schleger H, Oehninger NR, Reiter-Theil S. Avoiding bias in medical ethical decision-making. Lessons to be learnt from psychology research. Med Health Care Philos. 2011;14:155-62. https://doi.org/10.1007/s11019-010-9263-2

3. Zestcott CA, Blair IV, Stone J. Examining the presence, consequences, and reduction of implicit bias in health care: a narrative review. Group Process Intergroup Relat. 2016;19:528-42. https:// doi.org/10.1177/1368430216642029

4. Smedley BD, Stith AY, Nelson AR. Unequal treatment: confronting racial and ethnic disparities in health care. Washington, DC: National Academies Press; 2003.

5. Blair IV, Steiner JF, Havranek EP. Unconscious (implicit) bias and health disparities: where do we go from here? Perm J. 2011;15:71-8.

6. Dovidio JF, Fiske ST. Under the radar: how unexamined biases in decision-making processes in clinical interactions can contribute to health care disparities. Am J Public Health. 2012;102:945-52. https://doi.org/10.2105/ajph.2011.300601

7. Gonzalez CM, Deno ML, Kintzer E, Marantz PR, Lypson ML, McKee MD. Patient perspectives on racial and ethnic implicit bias in clinical encounters: implications for curriculum development. Patient Educ Couns. 2018;101:1669-75. https://doi.org/10.1016/j. pec.2018.05.016

8. Krahn GL, Walker DK, Correa-De-Araujo R. Persons with disabilities as an unrecognized health disparity population. Am J Public Health 2015;105(Suppl 2):S198-206. https://doi.org/10. 2105/AJPH.2014.302182
9. Olkin R. Could you hold the door for me? Including disability in diversity. Cult Divers Ethn Minor Psychol. 2002;8(2):130-7.

10. Devine PG, Forscher PS, Austin AJ, Cox WT. Long-term reduction in implicit race bias: a prejudice habit-breaking intervention. J Exp Soc Psychol. 2012;48:1267-78. https://doi.org/10. 1016/j.jesp.2012.06.003

11. Suchman AL, Matthews DA. What makes the patient-doctor relationship therapeutic? Exploring the connexional dimension of medical care. Ann Intern Med. 1988;108:125-30.

12. Abrantes-Pais Fde N, Friedman JK, Lovallo WR, Ross ED. Psychological or physiological: why are tetraplegic patients content? Neurology. 2007;69:261-7. https://doi.org/10.1212/01.wnl. 0000262763.66023.be

13. Devine PGPE. Advances in experimental social psychology. San Diego: Academic; 2012.

14. McConnell D, Hahn L, Savage A, Dube C, Park E. Suicidal ideation among adults with disability in western canada: a brief report. Community Ment Health J. 2016;52:519-26. https://doi. org/10.1007/s10597-015-9911-3

15. Haque OSS, Stein MA. Humanizing clinical care for patients with disabilities. In: Cohen IG, Shachar C, Silvers A, Stein MA, editors. Beyond disadvantage: disability, law, and bioethics. Cambridge: Cambridge University Press; 2020.

16. Hahn H. The politics of physical differences: disability and discrimination. J Soc Issues. 1988;44:39-47. https://doi.org/10.1111/ j.1540-4560.1988.tb02047.x

17. Park JH, Faulkner J, Schaller M. Evolved disease-avoidance processes and contemporary anti-social behavior: prejudicial attitudes and avoidance of people with physical disabilities. J Nonverbal Behav. 2003;27:65-87. https://doi.org/10.1023/A: 1023910408854

18. FitzGerald C, Hurst S. Implicit bias in healthcare professionals: a systematic review. BMC Med Ethics. 2017;18:19. https://doi.org/ 10.1186/s12910-017-0179-8

19. Gonzalez CM, Garba RJ, Liguori A, Marantz PR, McKee MD, Lypson ML. How to make or break implicit bias instruction: implications for curriculum development. Acad Med. 2018;93 (11S Association of American Medical Colleges Learn Serve Lead: Proceedings of the 57th Annual Research in Medical Education Sessions):S74-81. https://doi.org/10.1097/acm. 0000000000002386

20. Sabin J, Nosek BA, Greenwald A, Rivara FP. Physicians' implicit and explicit attitudes about race by MD race, ethnicity, and gender. J Health Care Poor Underserv. 2009;20:896-913. https://doi. org/10.1353/hpu.0.0185

21. Hodgins G, McSherry ML, Gibbs EP, Brosco J, Harvey PD. 3.37 The Debbie Project: reducing bias toward persons with disabilities. J Am Acad Child Adolesc Psychiatry. 2019;58: S206-7.

22. Galli G, Lenggenhager B, Scivoletto G, Molinari M, Pazzaglia M. Don't look at my wheelchair! The plasticity of longlasting prejudice. Med Educ. 2015;49:1239-47. https://doi.org/10.1111/ medu. 12834

23. Kripke C. Patients with disabilities: avoiding unconscious bias when discussing goals of care. Am Fam Physician. 2017;96:192-5.

24. Chapman EN, Kaatz A, Carnes M. Physicians and implicit bias: how doctors may unwittingly perpetuate health care disparities. J Gen Intern Med. 2013;28:1504-10. https://doi.org/10.1007/ s11606-013-2441-1

25. Blauwet CA. I use a wheelchair. And yes, i'm your doctor. New York Times; New York: NY; 2017. 